\title{
Huge yolk sac tumor in an adolescent girl: a case report
}

\author{
Amrita J. Jain*, Rekha G. Daver, Anjali M. Patil \\ Department of Obstetrics and Gynecology, Grant Government Medical College, Mumbai, Maharashtra, India
}

Received: 12 May 2017

Accepted: 10 June 2017

\section{*Correspondence:}

Dr. Amrita J. Jain,

E-mail: amritadby1901@gmail.com

Copyright: $\odot$ the author(s), publisher and licensee Medip Academy. This is an open-access article distributed under the terms of the Creative Commons Attribution Non-Commercial License, which permits unrestricted non-commercial use, distribution, and reproduction in any medium, provided the original work is properly cited.

\begin{abstract}
Germ cell tumours form a minority of all malignancies of the ovary. The common age group affected by yolk sac tumours is 11 to 24 years. Here, we present a case of yolk sac tumour in a 13-year-old girl who came with complaints of abdominal pain, distension and acute febrile illness. Fertility sparing surgery (Unilateral salpingo-oophorectomy) was done while the contra lateral ovary and uterus was conserved followed by combination chemotherapy postoperatively. As pprognosis of yolk sac tumours is highly stage-dependent, an early diagnosis can result in a drastic difference in the final outcome of the treatment of this highly aggressive disease. Besides the rarity of the tumour, the importance of the fact, that a vigilant and informed clinician can make an early and timely diagnosis of this condition even in girls of such a young age and make a drastic difference in the final outcome of the treatment, compels us to present this case.
\end{abstract}

Keywords: Alpha fetoprotein, chemotherapy, Yolk sac tumour

\section{INTRODUCTION}

Ovarian yolk sac tumour (YST), also known as ovarian endodermal sinus tumour, is the second most frequent malignant ovarian germ cell tumour just after dysgerminoma, with an incidence of approximately $1 \%$ of ovarian malignancies. ${ }^{1}$ They usually occur around the second decade of life, median age being 16-18 yrs. Serum alpha fetoprotein (AFP) is a useful tumour marker for diagnosis and monitoring recurrence. Because of its high progression, the 3 -year survival rate was $13 \%$ prior to the availability of chemotherapy. ${ }^{2}$

Cisplatin-based chemotherapy has dramatically improved the prognosis of ovarian YST. ${ }^{3}$ Overall, the 5-year survival and disease-free survival rates have now improved to $94 \%$ and $90 \%$, respectively. ${ }^{4}$ Because of its high effect on women of childbearing age, a therapy to preserve reproductive function is of utmost importance. In several retrospective reviews, fertility-sparing surgery has been demonstrated to be as effective as radical surgery. Unilateral salpingo-oophorectomy and postoperative combination chemotherapy, which have been proven to be feasible and safe while the contra lateral ovary and uterus are not affected, are now widely recommended in patients of reproductive age..$^{3-7}$

Here, we present a case of a thirteen-year-old girl with yolk sac tumour. Besides the rarity of the tumour, the importance of the fact, that a vigilant and informed clinician can make an early and timely diagnosis of this condition even in girls of such a young age and make a drastic difference in the final outcome of the treatment, compels us to present this case.

\section{CASE REPORT}

A 13-year-old girl, resident of Pune, Maharashtra was referred to our institute from a private clinician as a case of $13 \mathrm{yr}$ girl with? Fibroid? Left ovarian mass with acute 
febrile illness. Her complaints were pain in abdomen since, 3 months, abdominal distention since, 8 days and intermittent fever since, 8 days.

She came with a private ultrasound report which showed a large 20x $9 \mathrm{~cm}$ heterogeneous solid cystic lesion in Abdomino- pelvic region? Fibroid? Hemorrhage within Rt ovarian mass with bilateral hydronephrosis and hydroureter. On examination, she was cachexic and pale. Abdominal examination revealed a $20 \times 20 \mathrm{~cm}$ irregular solid, cystic mass occupying the whole of abdomen and non-tender.

Her haemoglobin was $8 \mathrm{gm} \%$ while other routine tests were within normal limits. Computed tomography of the abdomen revealed a large well defined abdomino pelvic solid cystic lesion of $25 \times 16 \times 13 \mathrm{~cm}$ on $\mathrm{rt}$ side. Rt ovary was not seen separately. There was minimal ascites, Rt pleural effusion, b/l hydronephrosis, multiple sub centimeter necrotic para-aortic and mesenteric lymphadenopathy (Figure 1). Tumor markers- Ca 125 381, AFP $>400$ ng/mL, Beta HCG $-<2$.

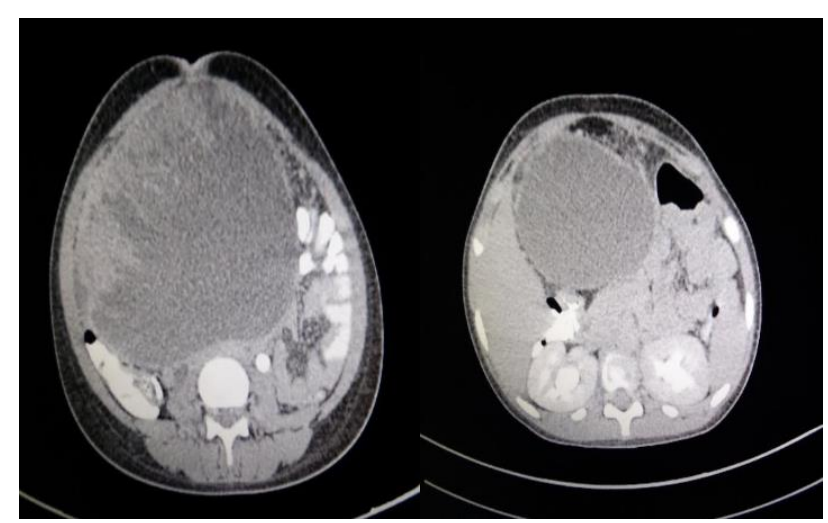

Figure 1: Transverse section of abdominal CT scan showing a large ovarian mass.

In the ward, patient continued to have fever of 102-103 0 F. Fever profile was negative, urine and blood culture did not reveal any organism. Sputum for acid fast Bacilli (AFB) was negative. USG guided ascitic fluid tap was done which on cytology showed no malignant cells. Ascitic fluid protein was $2800 \mathrm{mg} \%$ and sugar $18 \mathrm{mg} \%$. Inspite of higher antibiotics, patient continued to have fever. As per anesthetist, pt was unfit for any major surgery. On the other hand, the abdominal distension was increasing rapidly and the patient now started having breathlessness. Oncosurgeon's opinion was taken who attributed the high-grade fever as a sign of paraneoplastic syndrome and advised laparotomy despite all the risks.

Exploratory laparotomy revealed a huge Rt ovarian tumor $30 \times 30 \times 20 \mathrm{~cm}$ (Total Wt. $5 \mathrm{~kg}$ with 2 lit fluid) with adhesions to omentum and rectum (Figure 2, Figure 3). Excision of Huge Rt ovarian tumor with adhesiolysis, Omentectomy and Peritonectomy along with b/l pelvic lymphadenectomy was done. Left ovary, uterus and the other intra-abdominal organs were normal. Peritoneal fluid cytology was free of malignant cells. Frozen section was suggestive of malignant germ cell tumor. 3 units blood was given and she was kept in CCU for 3 days postoperatively due to electrolyte imbalance. Histopathology report revealed Yolk sac tumor of right ovary, with no evidence of tumor deposit in omentum but 1out of 3 pelvic lymph nodes on right side was positive for malignancy. Post-operative AFP level decreased drastically to $100 \mathrm{ng} / \mathrm{mL}$. Pt has received 3 cycles of chemotherapy (BEP regimen) till now and AFP has further decreased to $24 \mathrm{ng} / \mathrm{mL}$.

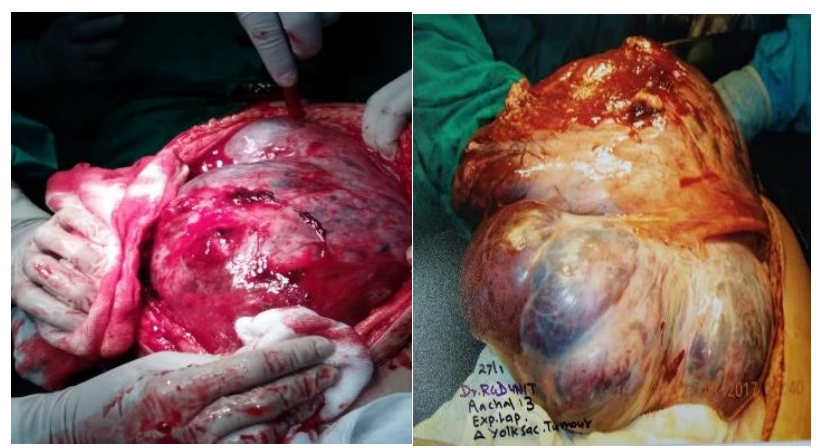

Figure 2: Intraoperative findings of huge rt ovarian tumor with adhesions to omentum and rectum.

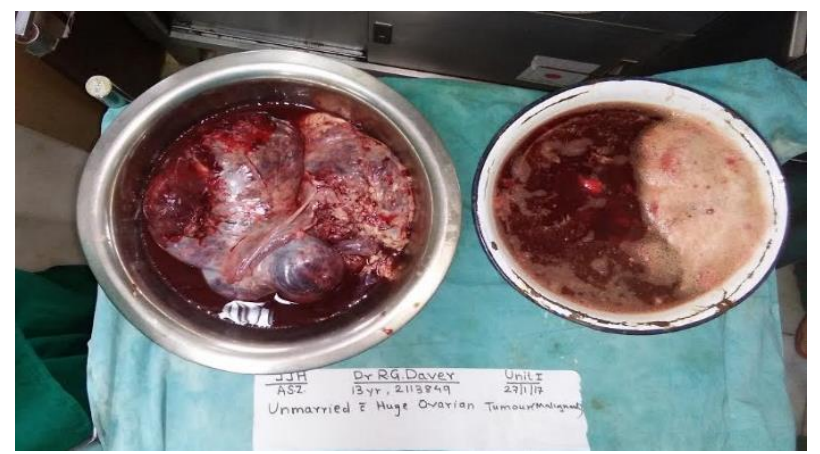

Figure 3: Cut section showing solid-cystic spaces (specimen wt $5 \mathrm{~kg}$ and 2 litre fluid).

\section{DISCUSSION}

Yolk sac tumors of the ovary are rare and highly malignant tumors of utmost importance occurring in children and young adults. ${ }^{8}$ They are classified into four patterns: endodermal sinus pattern, polyvesicular vitelline pattern, hepatoid pattern and glandular pattern. It is not too much to say that the Schiller-Duval body is a symbol of yolk sac tumors. ${ }^{9}$ Serum alpha-fetoprotein is a useful marker for the diagnosis and management of YST. YSTs are highly aggressive tumors with poor prognosis and were almost always fatal till the refinement of chemotherapeutic regimens in the past few decades. Survival rates have improved substantially, especially for stage I and II disease. Keeping the fact in mind that YST occurs in young age, fertility of the patient usually needs to be preserved and the optimal surgery done is 
laparotomy with unilateral salpingo-oophorectomy, peritoneal cytologic studies, omentectomy, multiple peritoneal and abdominal biopsies and resection of all visible disease. Three to four courses of post-operative chemotherapy consisting of bleomycin, etoposide and cisplatin are given keeping in consideration the bulk of residual disease.

\section{CONCLUSION}

This is an interesting case of yolk sac tumor in a young girl at the age typical of germ cell tumor. Though diagnosis was quite clear in view of raised AFP and CT findings, high grade fever and anemia made her unfit for surgery. However, surgery was done explaining the high risks to the relatives. It was a difficult surgery due to omental and rectal adhesions and also postoperative electrolyte imbalance needed intensive care management for 3 days. In young age with High AFP levels and rapidly growing ovarian mass, diagnosis of the Yolk sac tumor has to be kept in mind. As yolk sac tumor is $100 \%$ unilateral, contra lateral ovary should be conserved. Initial surgery followed by adjuvant chemotherapy including Bleomycin, Etoposide, and Cisplatin is considered as standard treatment of yolk sac tumor. With definitive surgery and chemotherapy yolk sac tumor is no more a night mare!

Funding: No funding sources Conflict of interest: None declared Ethical approval: Not required

\section{REFERENCES}

1. Dallenbach P, Bonnefoi H, Pelte MF. Yolk sac tumours of the ovary: an update. Eur J Surg Oncol. 2006;32:1063-1075.
2. Kurman RJ, Norris HJ. Endodermal sinus tumor of the ovary: a clinical and pathologic analysis of 71 cases. Cancer. 1976;38:2404-19.

3. de la Motte RT, Pautier P, Rey A. Prognostic factors in women treated for ovarian yolk sac tumour: a retrospective analysis of 84 cases. Eur J Cancer. 2011;47:175-82.

4. de la Motte RT, Pautier P, Duvillard P, et al. Survival and reproductive function of 52 women treated with surgery and bleomycin, etoposide, cisplatin (BEP) chemotherapy for ovarian yolk sac tumor. Ann Oncol. 2008;19:1435-41.

5. Liu Q, Ding X, Yang J. The significance of comprehensive staging surgery in malignant ovarian germ cell tumors. Gynecol Oncol. 2013;131:551-4.

6. Cicin I, Saip P, Guney N. Yolk sac tumours of the ovary: evaluation of clinicopathological features and prognostic factors. Eur J Obstet Gynecol Reprod Biol. 2009;146:210-4.

7. Nawa A, Obata N, Kikkawa F. Prognostic factors of patients with yolk sac tumors of the ovary. Am J Obstet Gynecol. 2001;184:1182-8.

8. Dällenbach P, Bonnefoi H, Pelte MF, Vlastos G. Yolk sac tumours of the ovary: an update. Eur J Surg Oncol. 2006;32:1063-75.

9. Hiroshi H, Machiko T, Tomohiko K, Terumasa S, Satoshi Y, Kazuo H. A case of yolk sac tumor of the ovary. Bulletin of Hyogo Medical Center for Adults. 1996;13:33-5.

Cite this article as: Jain AJ, Daver RG, Patil AM. Huge yolk sac tumor in an adolescent girl: a case report. Int J Reprod Contracept Obstet Gynecol 2017;6:3192-4. 